\title{
Osteoporosis resulting from acute lymphoblastic leukemia in a 7-year-old boy: a case report
}

\author{
Hendra Salim ${ }^{1 *}$, Ketut Ariawati ${ }^{1}$, Wayan Bikin Suryawan ${ }^{2}$ and Made Arimbawa ${ }^{2}$
}

\begin{abstract}
Introduction: Osteoporosis in children is rare and usually secondary to an underlying disease process whose diagnosis may be difficult to detect. Etiological factors responsible for osteoporosis secondary to chronic illness include immobility, pubertal delay and other hormonal disturbances. Rarely, it can be a manifestation of acute lymphoblastic leukemia. Most of the reported bone fracture incidences associated with acute lymphoblastic leukemia occur during the course of the chemotherapy, not at the point of the first symptoms of leukemic disease, as happened with the case presented here.
\end{abstract}

Case presentation: A 7-year-old Asian Balinese boy presented with back pain. His anteroposterior pelvic radiograph showed osteoporotic bone. A bone age study revealed growth failure of his metacarpals, phalanges and sesamoid. His total bone mass density was 97\% age-match. However, a peripheral blood smear showed normochromic anemia with thrombocytopenia. Immunophenotyping of his peripheral blood revealed no dominant markers, but a bone marrow aspiration confirmed a diagnosis of acute lymphoblastic leukemia.

Conclusions: Osteoporosis was the only manifestation of the child's underlying acute lymphoblastic leukemia. Leukemia was diagnosed when his bone marrow was found to contain more than 25\% blasts. Because of leucopenia, the immunophenotype failed to reveal a dominant marker in this case, thus we were unable to classify the acute lymphoblastic leukemia.

Keywords: Acute lymphoblastic leukemia, Children, Osteoporosis

\section{Introduction}

Normal bone mass is defined by the World Health Organization as a bone mass density (BMD) within one standard deviation (SD) of the mean for young adults, osteopenia as increased bone loss with a bone mass between 1 and 2.5 SDs below normal, and osteoporosis as a bone mass $\geq 2.5$ SDs below normal. There is no consensus about the definition of osteoporosis in pediatrics. Most bone specialists make a diagnosis of osteoporosis in children and adolescents only when BMD is low and there is at least one fracture $[1,2]$.

Childhood osteoporosis may arise from an intrinsic genetic bone abnormality (primary osteoporosis) or an underlying medical condition and/or its treatment (secondary osteoporosis). The primary forms are relatively rare,

\footnotetext{
* Correspondence: misionarispelayanan@yahoo.com

'Division of Hematology and Oncology, Department of Child Health, Medical Faculty of Udayana University, Sanglah Hospital, Kesehatan Street No. 1, Denpasar, Bali, Indonesia

Full list of author information is available at the end of the article
}

whereas secondary forms of osteoporosis are increasingly observed in many chronic conditions [3]. Etiological factors responsible for osteoporosis secondary to chronic illness include immobility, pubertal delay and other hormonal disturbances, undernutrition and low body weight, inflammatory cytokines and glucocorticoid use $[2,4]$.

Leukemia is the most common form of childhood malignancy, with acute lymphoblastic leukemia (ALL) accounting for approximately $75 \%$ of cases. With an overall survival rate approaching $80 \%$, children with ALL have an excellent prognosis [3]. The two major skeletal complications of leukemia are osteoporosis and avascular necrosis [5].

Kaste et al. [6] revealed a bone mineral accumulation process during the period corresponding to onset of most childhood ALLs. Haddy et al. [7] noted that osteopenia/ osteoporosis was observed in all phases of the disease: at diagnosis, during treatment, and throughout the posttreatment period for as long as 20 years. Among the findings that have been described are musculoskeletal pain, disturbed gait, fractures, kyphosis, lordosis, and growth 
failure. Pathologic fractures and vertebral collapses secondary to severe osteopenia (leukemic osteopathy) may occur [8].

Strauss et al. [5] reported a 28\% 5-year cumulative fracture incidence in children with ALL. Rogalsky et al. [9] reported fractures in $25 \%$ of children with acute leukemia, $12 \%$ pathological, and 13\% following trauma, during the course of their disease. Halton and Atkinson [10] reported that $39 \%$ of children with ALL had fractures by completion of their therapy.

An increased fracture frequency was also reported by van der Sluis et al. [11], who found the fracture rate in children with ALL to be six times that of healthy controls, up to 12 months following chemotherapy. Bone mass is often reduced at diagnosis in ALL and falls significantly during the first 6 months of chemotherapy [11,12]. Risk factors for the development of skeletal complications in ALL include poor nutrition, reduced mobility, impaired bone mineralization, older age at diagnosis and being of male gender $[5,10]$.

About two-thirds of children with ALL will have had signs and symptoms of disease for less than 4 weeks at the time of their diagnosis. However, a history of some months is also compatible with the diagnosis of ALL. The first symptoms are usually nonspecific and include lethargy, unrelenting fatigue, bone pain or loss of appetite. More specific symptoms such as anemia, hemorrhage and infections are a consequence of lymphoblasts occupying the bone marrow and disturbing the residual normal hematopoiesis [8].

Bone pain is one of the initial symptoms in childhood ALLs that may result from direct leukemic infiltration of the periosteum, bone infarction, or expansion of the marrow cavity by leukemic cells. In normal hematopoiesis, hematopoietic stem cells (HSCs) are in balance with components of the hematopoietic microenvironment including osteoblastic cells, osteoclasts, mesenchymal cells, and vascular structures. In leukemia, invasion of leukemia cells results in osteopenia mediated by an expansion of osteoclasts causing increased bone reabsorption and a concomitant reduction of osteoblastic activity [13].

\section{Case presentation}

A 7-year-old Asian Balinese boy was referred to our hospital because of persistent back pain over a 2-month period. The pain increased when he walked, but disappeared when he rested.

His respiratory rate was 26 breaths per minute, no cyanotic was noted, his heart rate was 96 beats per minute, and no grunting was noted. His axillaries temperature was $37^{\circ} \mathrm{C}$. He had pale conjunctiva. He also had multiple lymphadenopathies to the right and left of both the abdominal and inguinal regions. The lymphadenopathies were mobile, with no sign of inflammation. There was no retraction on thorax region. We noticed an innocent murmur on auscultation, grade II/6. No enlargement of the liver or spleen was found. He had no rash, petechia nor edema on his extremities.

His weight was $18.5 \mathrm{~kg}$ ( $<3 \mathrm{rd}$ percentile for his age, Centers for Disease Control and Prevention, CDC, 2000). His height was $118 \mathrm{~cm}$ (his stature for his age puts him in the 10th to 25th percentile, CDC 2000), and head circumference was $50 \mathrm{~cm}$. His nutritional status was $84 \%$ according to Waterlow. According to his parents' height (his father's height was $173 \mathrm{~cm}$, his mother's height was $165 \mathrm{~cm}$ ), his potential adult height would be around 167 to $184 \mathrm{~cm}$. His upper segment was $66 \mathrm{~cm}$ and lower segment was $52 \mathrm{~cm}$. The upper-lower segment ratio was thus 1.27.

His initial complete blood count revealed a normal white blood cell (WBC) count $\left(11.59 \times 10^{3} / \mathrm{uL}\right)$, with low hemoglobin level $(8.2 \mathrm{~g} / \mathrm{dL})$. His mean corpuscular volume was $80.2 \mathrm{fL}$. His platelet count was $41 \times 10^{3} / \mathrm{uL}$. A review of a peripheral blood smear showed a normochromic anemia with thrombocytopenia. His free thyroxine and thyroid-stimulating hormone levels were $1.56 \mathrm{ng} / \mathrm{dL}$ and $3.24 \mathrm{uIU} / \mathrm{mL}$, respectively. His parathyroid hormone level was $14.09 \mathrm{pg} / \mathrm{mL}$. His calcium $=9.10 \mathrm{mg} / \mathrm{dL}$, sodium $=136.10 \mathrm{mmol} / \mathrm{L}$, potassium $=4.33 \mathrm{mmol} / \mathrm{L}$, uric acid $=4.1 \mathrm{mg} / \mathrm{dL}$, total bilirubin $=0.22 \mathrm{mg} / \mathrm{dL}$, direct bilirubin $=0.1 \mathrm{mg} / \mathrm{dL}$, alanine aminotransferase $=21.99 \mathrm{U} / \mathrm{L}$, aspartate aminotransferase $=10.7 \mathrm{U} / \mathrm{L}$, albumin $=3.65 \mathrm{~g} /$ $\mathrm{dL}$, urea $=13.2 \mathrm{mg} / \mathrm{dL}$ and creatinine serum $=0.41 \mathrm{mg} / \mathrm{dL}$. His serum iron was $133.9 \mathrm{ug} / \mathrm{dL}$, total iron binding capacity was $214 \mathrm{ug} / \mathrm{dL}$ and ferritin was $282.7 \mathrm{ng} / \mathrm{mL}$.

At first, the differential diagnosis was either osteoporosis with chronic infection or aplastic anemia. A tuberculin test was performed, and the result was negative. A posteroanterior and a lateral thorax radiograph showed multiple compressions of thoracic vertebrae. An anteroposterior pelvic radiograph showed osteoporosis. The thoracic vertebrae magnetic resonance imaging (MRI) showed multiple wedge and biconcave compressions of his left thoracal corpus vertebra and fatty marrow replacement in the osteoporotic bone marrow (Figure 1). He was treated daily with a $200 \mathrm{mg}$ oral dose of calcium for the osteoporosis.

His bone age, according to the S. Idell Pyle atlas, showed growth failure of his metacarpals, phalanges and sesamoid. His spine $\left(0.482 \mathrm{~g} / \mathrm{cm}^{2}\right)$ and total body BMD $\left(0.805 \mathrm{~g} / \mathrm{cm}^{2}\right)$ were normal, with a $97 \%$ age-match and a $\mathrm{Z}$ score of $-0.5 \mathrm{SD}$.

One month later, his complete blood count showed pancytopenia (white blood count $=3.54 \times 10^{3} / \mathrm{uL}$, hemoglobin $=9.9 \mathrm{~g} / \mathrm{dL}$ and thrombocyte $=37.2 \times 10^{3} / \mathrm{uL}$ ). His mean corpuscular volume was $86.4 \mathrm{fL}$. He had a bone marrow aspiration and the results revealed ALL (L2). The sample was hypercellular, with round and oval nucleus shape, smooth homogeneous chromatin, and high nuclear- 


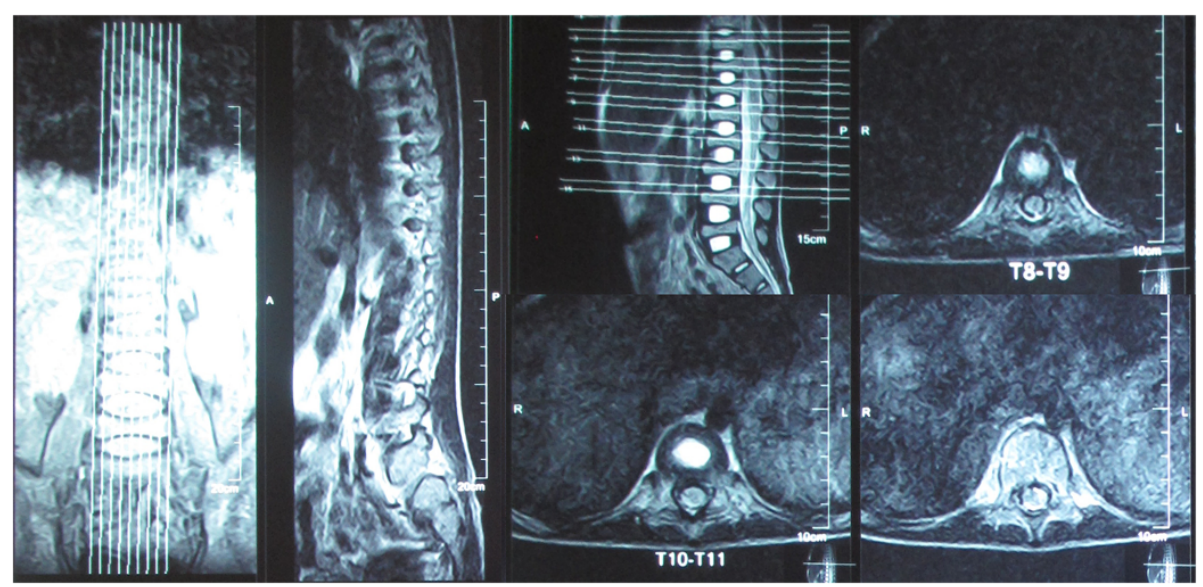

Figure 1 Magnetic resonance-imaging of the spine, 1 week after admission, revealed multiple wedge and biconcave compressions.

cytoplasmic ratio. There were low activities in his erythroid, myeloid and megakaryocytic system (Figure 2). We noticed a 50\% lymphoblast cell infiltration with size variations. The immunophenotyping of peripheral blood revealed no dominant markers.

Based on the bone marrow aspiration, a diagnosis of ALL (L2) was made, excluding aplastic anemia and chronic infection anemia. He had serial chemotherapy for 109 weeks, with calcium and vitamin D supplements for the leukemia and secondary osteoporosis.

\section{Conclusions}

In this case, the whole body BMD was decreased by 0.5 SD. Prospective studies have shown that a decrease in

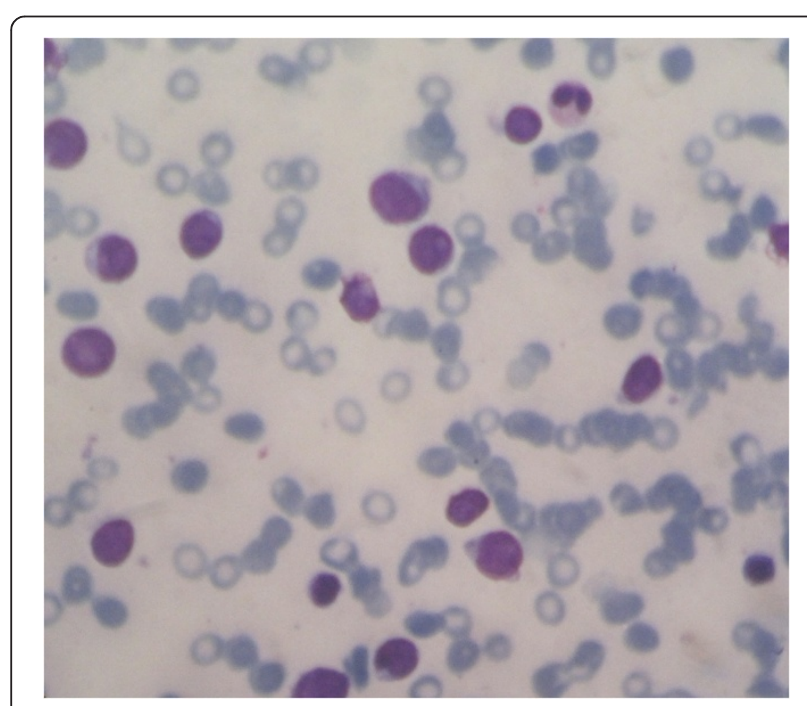

Figure 2 Histological examination of a bone marrow aspiration, taken 1 month after admission, revealed acute lymphoblastic leukemia (L2). The cytological feature revealed large-heterogeneous cells, with homogeneous nuclear chromatin, one or more nucleoli, and low activity in the erythroid, myeloid and megakaryocytic system.
BMD by $1 \mathrm{SD}$ is associated with a 1.5- to 3 -fold increase in the relative risk of fracture [6,7]. The bone age assessment revealed a growth failure of the metacarpals, phalanges and sesamoid. Multiple compressions were seen in the posteroanterior and lateral thorax radiograph, the anteroposterior pelvic radiograph, and the thoracic vertebrae MRI, which signified osteoporosis.

For childhood ALLs, the WBC count may be low, normal, or increased. Our case had an initially normal WBC count, but it then dropped to $3.54 \times 10^{3} / \mathrm{uL}$. The hemoglobin level usually shows a moderate to marked reduction, with a normocytic normochromic red cell morphology. Blood smears for ALL with leucopenia usually show very few to no blasts, but when the WBC is greater than $10^{4} / \mathrm{mm}^{3}$, blasts are usually abundant. In our case the first blood smear showed normochromic anemia with thrombocytopenia. Both the blood smear and the immunophenotyping in this case revealed no blasts.

Leukemia is diagnosed when the bone marrow contains more than 25\% blasts. Megakaryocytes are usually absent. The hallmark of the diagnosis of acute leukemia is blast cells, a relatively undifferentiated cell with diffusely distributed nuclear chromatin, one or more nucleoli, and basophilic cytoplasm. In this case, a bone marrow aspiration revealed hypercellularity and low activity in the erythroid, myeloid and megakaryocytic systems, with 50\% lymphoblast cell infiltration.

There is a difference between normal hematopoiesis and leukemia in bone homeostasis. In normal hematopoiesis, HSCs are in balance with components of the hematopoietic microenvironment including osteoblastic cells, osteoclasts, mesenchymal cells, and vascular structures. In leukemia, invasion of leukemia cells results in osteopenia mediated by an expansion of osteoclasts causing increased bone reabsorption and a concomitant reduction of osteoblastic activity. The effect, if any, on 
other components of the HSC niche has yet to be determined [13].

Specialist studies such as immunophenotyping usually help in detailed leukemic subtype classification. Unfortunately, because of the leucopenia, the immunophenotype failed to reveal a dominant marker in this case, thus we were unable to classify the ALL.

\section{Consent}

Written informed consent was obtained from the patient's legal guardian(s) for publication of this case report and any accompanying images. A copy of the written consent is available for review by the Editor-in-Chief of this journal.

\section{Abbreviations}

ALL: Acute lymphoblastic leukemia; BMD: Bone mass density; CDC: Centers for Disease Control and Prevention; HSC: Hematopoietic stem cell; MRI: Magnetic resonance imaging; SD: Standard deviation; WBC: White blood cell.

\section{Competing interests}

The authors declare that they have no competing interests.

\section{Authors' contributions}

KA analyzed the patient data regarding the hematological disease. WBS interpreted the physical and laboratory examinations of the patient. MA evaluated the physical and radiological examinations regarding the osteoporosis disease. HS performed the histological examination of the bone marrow, and was a major contributor in writing the manuscript. All authors read and approved the final manuscript.

\section{Acknowledgements}

The authors would like to thank Nyoman Wande MD and Anak-Agung Wiradewi Lestari MD for help in verification in the histological examination of bone marrow. The authors also thank Bagus-Ngurah-Putu Arhana MD and Ketut Suarta MD for their extensive consent for the collection of data.

\section{Author details}

'Division of Hematology and Oncology, Department of Child Health, Medical Faculty of Udayana University, Sanglah Hospital, Kesehatan Street No. 1, Denpasar, Bali, Indonesia. ${ }^{2}$ Division of Endocrinology, Department of Child Health, Medical Faculty of Udayana University, Sanglah Hospital, Kesehatan Street No. 1, Denpasar, Bali, Indonesia.

Received: 5 November 2013 Accepted: 10 March 2014 Published: 28 May 2014

\section{References}

1. Plotkin H, Lifshitz F: Rickets and osteoporosis. In Pediatric Endocrinology. 5th edition. Edited by Lifshitz F. USA: Informa Healthcare; 2007:531-548.

2. Bianchi ML: Osteoporosis in children and adolescents. Bone 2007, 41:486-495.

3. Crist WM, Smithson WA: The leukemias. In Nelson Textbook of Pediatrics. 16th edition. Edited by Behrman RE, Kliegman RM, Jenson HB. Philadelphia: W.B. Saunders; 2000:1543-1548

4. Munns CFJ, Cowell CT: Prevention and treatment of osteoporosis in chronically ill children. J Muscoloskelet Neuronal Interact 2005, 5:262-272.

5. Strauss AJ, Su JT, Dalton VM, Gelber RD, Sallan SE, Silverman LB: Bony morbidity in children treated for acute lymphoblastic leukemia. J Clin Oncol 2001, 19:3066-3072.

6. Kaste SC, Jones-Wallace D, Rose SR, Boyett JM, Lustig RH, Rivera GK, Pui CH, Hudson MM: Bone mineral decrements in survivors of childhood acute lymphoblastic leukemia: frequency of occurrence and risk factors for their development. Leukemia 2001, 15:728-734.

7. Haddy TB, Mosher RB, Reaman GH: Osteoporosis in survivors of acute lymphoblastic leukemia. Oncol 2001, 6:278-285.
8. Smith OP, Hann IM: Clinical features and therapy of lymphoblastic leukemia. In Pediatric Hematology. 3rd edition. Edited by Arceci RJ, Hann IM, Smith OP. Australia: Blackwell Publishing; 2006:450-481.

9. Rogalsky RJ, Black GB, Reed MH: Orthopaedic manifestations of leukemia in children. J Bone Joint Surg 1986, 68:494-501.

10. Atkinson SA, Halton JM, Bradley C, Wu B, Barr RD: Bone and mineral abnormalities in childhood acute lymphoblastic leukemia: influence of disease, drugs and nutrition. Int J Cancer 1998, 11(suppl):35-39.

11. van der Sluis IM, van den Heuvel-Eibrink MM, Hahlen K, Krenning EP, de Muinck Keizer-Schrama SM: Altered bone mineral density and body composition, and increased fracture risk in childhood acute lymphoblastic leukemia. J Pediatr 2002, 141:204-210.

12. Halton JM, Atkinson SA, Fraher L, Webber C, Gill GJ, Dawson S, Barr RD: Altered mineral metabolism and bone mass in children during treatment for acute lymphoblastic leukemia. J Bone Miner Res 1996, 11:1774-1783

13. Lane SW: Bad to the bone. Blood 2012, 119:323-325.

doi:10.1186/1752-1947-8-168

Cite this article as: Salim et al:: Osteoporosis resulting from acute lymphoblastic leukemia in a 7-year-old boy: a case report. Journal of Medical Case Reports 2014 8:168.

\section{Submit your next manuscript to BioMed Central and take full advantage of:}

- Convenient online submission

- Thorough peer review

- No space constraints or color figure charges

- Immediate publication on acceptance

- Inclusion in PubMed, CAS, Scopus and Google Scholar

- Research which is freely available for redistribution 